\title{
Effect of Preprocedural Intravenous Ibuprofen on Post-Repair Pain after Traumatic Wound Management: A Randomized Clinical Trial
}

\author{
${ }^{1}$ Assistant Professor, Trauma and Injury Research Center, Iran University of Medical Sciences, Tehran, Iran \\ ${ }^{2}$ Assistant Professor, Emergency Medicine Department, Iran University of Medical Sciences, Tehran, Iran \\ ${ }^{3}$ Assistant Professor, Trauma and Injury Research Center, Iran University of Medical Sciences, Tehran, Iran \\ ${ }^{4}$ School of Medicine, Alborz University of Medical Sciences, Karaj, Iran \\ ${ }^{5}$ Assistant Professor, Emergency Department, Qazvin University of Medical Sciences, Qazvin, Iran
}

Hossein Shaker ${ }^{1}$, Mohammad Hossein Rezaei², Hamed Basir Ghafouri³ ${ }^{3}$ Niloofar Abazarian ${ }^{4}$ and Ehsan Modirian ${ }^{5, *}$

* Corresponding author: Ehsan Modirian, Emergency Department, Qazvin University of Medical Sciences, Qazvin, Iran. Tel: +989123406808; Email: ehsanmodirian@gmail.com,

Received 2021 February 12; Revised 2021 June 24; Accepted 2021 August 01

\begin{abstract}
Background: Wound repair cause extra pain and inflammation and can lead to post-repair discomfort in patients. Previous studies have indicated that pre-operative use of NSAIDs may reduce post-surgery pain; however, there is a dearth of data on traumatic wound repair. Objectives: This study aimed to investigate the effect of intravenous Ibuprofen on patient satisfaction and pain relief following wound repair.

Methods: Based on the inclusion and exclusion criteria, 194 participants in this double-blind randomized controlled trial were randomly assigned to either intervention or control group. Ibuprofen $800 \mathrm{mg}$ was infused in $100 \mathrm{cc}$ normal saline before wound repair in the intervention group, while the control group received $100 \mathrm{cc}$ normal saline. Numeric pain scores were recorded at the beginning of wound repair and 30 min after that. Patients' satisfaction with analgesia was also recorded 15 min after the drug infusion, during wound repair, and $6 \mathrm{~h}$ after the wound repair.

Results: Mean pain scores were similar in both groups during the wound repair, and before the application of local anesthesia (i.e. lidocaine). However, the mean pain score was significantly lower in patients who received Ibuprofen (3.86 \pm 1.93 ), compared to the control group (4.46 \pm 1.89$)$, 30 min after the wound repair $(\mathrm{P}=0.043)$. Patients' satisfaction with pain management $6 \mathrm{~h}$ after the wound repair was higher in the intervention $(\mathrm{P}=0.000)$, compared to the control group.

Conclusion: Based on the obtained results, the application of IV Ibuprofen before the wound repair can reduce pain score after the wound repair and lead to improved patients' satisfaction.
\end{abstract}

Keywords: Emergency, Ibuprofen, Pain, Trauma, Wound

\section{Background}

Traumatic wounds are common causes of emergency visits to health care centers. Wound suturing was performed in $2.5 \%$ of all emergency visits in the US in 2016 that makes it the $4^{\text {th }}$ most common procedure performed at emergency departments (ED) (1). Based on the evidence, patients' priorities in wound management include infection prevention, restoration of normal function, satisfactory cosmetic outcome, and minimal pain (2). Proper pain management can minimize physical and emotional damage. There are several pharmacological and non-pharmacological pain management methods for traumatic wounds including topical, local, and regional anesthesia. Moreover, oral, intravenous, intranasal, and respiratory analgesics are used as well $(3,4)$. Various studies are available on the application of local and regional anesthesia in wound repair procedure (3-8); however, there are limited data on post-repair pain. Cycloxigenase 2 (COX2) is an inducible enzyme and its expression is increased by tissue injury. COX2 mediates inflammation, pain, fever, and carcinogenic responses by increased synthesis of pro-inflammatory prostaglandins. It is widely known that COX inhibition is responsible for non-steroidal anti-inflammatory drugs (NSAID) main anti-inflammatory and pain relief mechanism of action. However, the COX independent antiinflammatory mechanisms have been discussed in some studies as well (9-10). In addition to tissue injury caused by the trauma, the process of wound management and repair (i.e. debridement, rubbing for irrigation, and suturing) can trigger an additional inflammatory response by excessive expression of COX2 and prostaglandins due to inevitable soft tissue damage. Therefore, it should be noted that the application of NSAIDs before suturing may decrease pain and inflammation after wound repair.

The results of previous studies indicated that preoperative use of NSAIDs can reduce postoperative pain (11-14); however, there is a dearth of data on traumatic wound repair.

The usual dose of Ibuprofen, as the most commonly used and most frequently prescribed NSAID, is $400-800 \mathrm{mg}$ three times a day (15). Ibuprofen is available in oral and intravenous forms. The terminal half-life of IV ibuprofen appears to be slightly more than $2 \mathrm{~h}$ and consistent across all 
dosing ranges (16). Like some other NSAIDs, there is evidence that the preoperative use of Ibuprofen is useful for the reduction of post-operative pain and the need for rescue analgesics (17-21).

\section{Objectives}

Therefore, this study aimed to investigate the effect of intravenous Ibuprofen on patient satisfaction and pain relief following the wound repair.

\section{Methods}

\subsection{Study design and setting}

This double-blind randomized controlled trial was conducted at Haftome Tir Hospital, a major referral and trauma center in Tehran, Iran. Data gathering started in December 2018 and ended in April 2019. This trial was registered at the Iranian clinical trial registry (IRCT20120613010017N8). Informed consent was obtained from all participants before the enrollment in the study. The study was approved by the Ethics Committee of the Iran University of Medical Sciences, Tehran, Iran, and carried out according to the Declaration of Helsinki [1989].

\subsection{Participants}

The study participants included patients in the age range of 15-75 years who were referred to ED of Haftome Tir Hospital (with no companion) for the simple skin lacerations of at least $2 \mathrm{~cm}$ length major injury.

Patients with animal and human bites, blast injury, crush wounds, amputations, tendon injury, open fractures, intraarticular involvement, fingertip laceration, decreased level of consciousness, history of allergy to NSAIDs, ischemic heart disease, ischemic cerebral disease, history of gastric ulcer or gastrointestinal bleeding, vascular diseases, renal insufficiency, single kidney, renal transplant, as well as immune-compromised patients, and those who received any kind of analgesics or opium during last 18 hours were excluded from the study.

\subsection{Sample size calculation}

The sample size was calculated to be 86 for each group using $\mathrm{G}$ power software to detect a $50 \%$ or greater difference in the primary outcome between the two study groups, with an $\alpha$ and $\beta$ of 0.05 and 0.1 ( $90 \%$ power), respectively.

\subsection{Randomization and blinding}

Randomization was performed using a computer-generated sequence table under the supervision of an emergency medicine physician who was in charge of the study. The process of patient selection and randomized allocation was performed by a PGY3 EM resident. The allocation was performed through the blind matching of the patient's number and package. Packages contained either $800 \mathrm{mg}$ intravenous Ibuprofen or injectable sterile water (as a placebo). Attending emergency physician supervised package preparation and concealment session. After matching of patients and packages numbers, the emergency nurse prepared the injection solution containing Ibuprofen or placebo in IV infusion sets with the same appearance. Participants and research investigators (PGY3 EM residents) were blinded to the content and preparation of the injection solution. The data analyzer was also blinded in this study.

\subsection{Intervention}

The research investigator (PGY3 EM resident) enrolled eligible participants based on inclusion and exclusion criteria after triage and admission. Informed written consent was obtained from the participants after the study objectives were explained to them. Participants were then randomly assigned into two groups of intervention and control. The intervention group received an IV infusion set containing Ibuprofen $800 \mathrm{mg}$ (Samen pharmaceutical Co., Iran) in $100 \mathrm{cc}$ normal saline, and the placebo group received an IV infusion set containing $100 \mathrm{cc}$ normal saline (both infused over $10 \mathrm{~min}$ ).

Wound closure by suture was performed 2-3 min following $30 \mathrm{~min}$ local anesthesia conducted by lidocaine $2 \%$ injected at wound edges.

\subsection{Outcome assessment}

The study investigator (PGY3 resident) asked patients to report the severity of their pain using a numeric rating scale $(0=$ no pain, $10=$ the most severe pain) at the beginning and $30 \mathrm{~min}$ after the wound closure. Patients' satisfaction with analgesia was also measured 15 min after drug infusion, during wound closure, and $6 \mathrm{~h}$ after wound closure using a verbal rating scale from 1 to 5 ( $1=$ Very bad, $2=\mathrm{Bad}$, $3=$ Rather bad, 4=Good, and 5=Excellent). Most patients were discharged from ED early after wound closure, and their satisfaction was recorded by phone call $6 \mathrm{~h}$ after the wound closure.Participants' demographic characteristics and outcome measures were recorded in pre-prepared data collection sheets.

\subsection{Statistical analysis}

Data were analyzed using SPSS software (SPSS, Inc., Chicago, IL; Version 23). Descriptive variables were presented as frequencies and means $\pm S D$. The normality of data distribution was tested using the Kolmogorov-Smirnov test. The parametric and nonparametric analysis was performed using the independent t-test and Mann-Whitney's test, respectively. A p-value less than 0.05 was considered statistically significant. 


\section{Results}

In total, 230 patients attended ED with traumatic lacerations from whom 34 patients were excluded based on the exclusion criteria. Afterward, 97 patients were assigned to each group of intervention and control using a random assignment approach. CONSORT flow diagram and baseline characteristics are provided in Figure 1 and Table 1, respectively. The mean \pm SD age of participants was $35.52 \pm 12.83$, and the majority $(90.2 \%)$ of them were male. The mean \pm SD time interval from the injury to ED attendance was $97.7 \pm 85.98 \mathrm{~min}$. It is worth mentioning that, $29.9 \%, 24.4 \%, 19.5 \%$, and $15.8 \%$ of patients were presented with the scalp, upper limb, lower limb, and face lacerations, respectively.

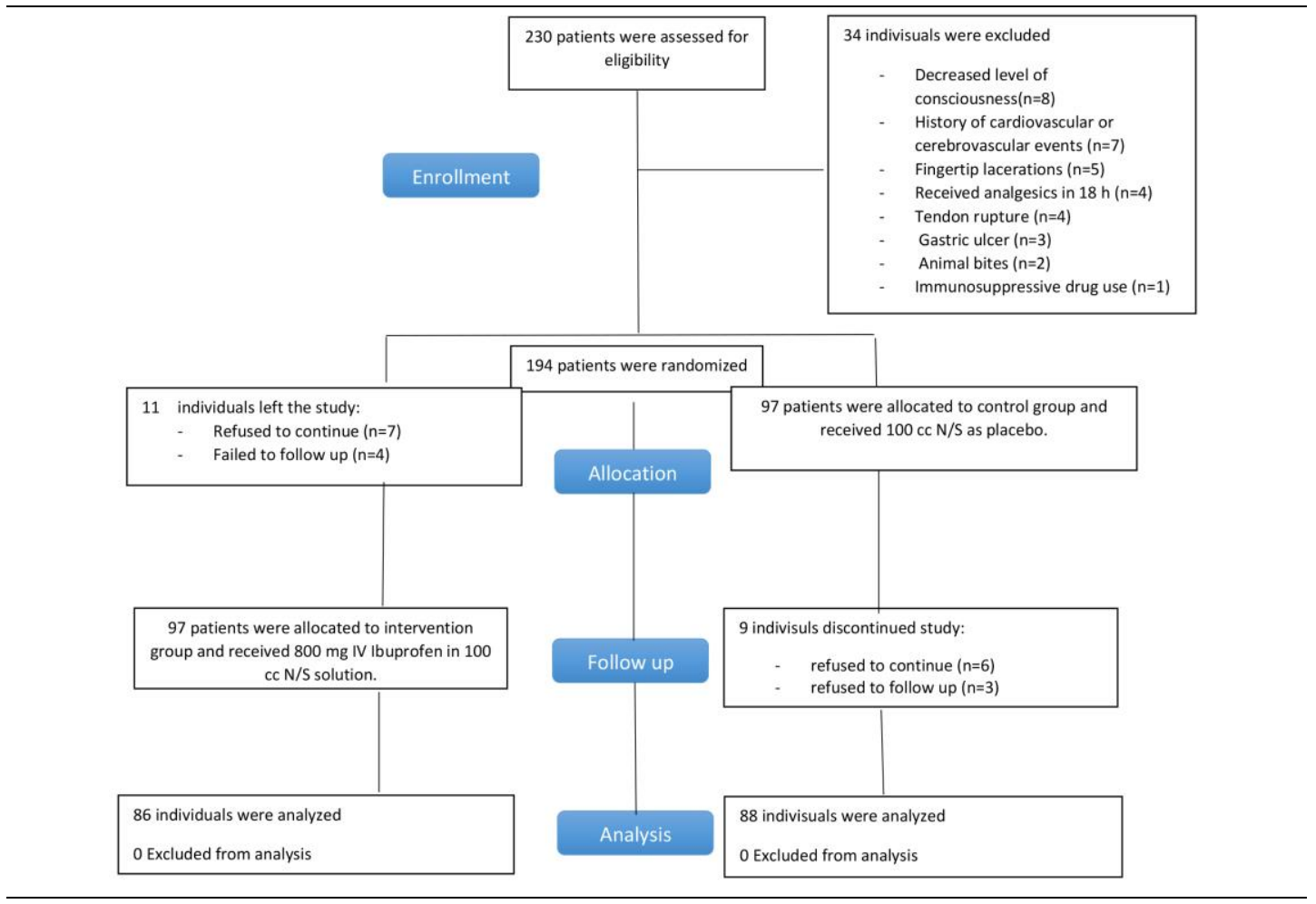

\begin{tabular}{|c|c|c|c|}
\hline Figure1.CONSORT flo & & & \\
\hline Table 1. Baselir & istics & & \\
\hline & Intervention Group & Placebo Group & P-Value \\
\hline Age & $33.71 \pm 12.64$ & $37.71 \pm 12.80$ & 0.04 \\
\hline Male & & & \\
\hline Gender & $85(81 \%)$ & $72(91 \%)$ & 0.714 \\
\hline Female & $10(19 \%)$ & $7(9 \%)$ & \\
\hline Wound length & $6.58 \pm 4.87$ & $6.01 \pm 2.46$ & 0.356 \\
\hline Wound depth & $1.08 \pm 0.85$ & $1.22 \pm 0.60$ & 0.263 \\
\hline
\end{tabular}

\begin{tabular}{|c|c|c|c|}
\hline & Intervention Group & Placebo Group & P-Value \\
\hline Pain score during wound closure & $6.91 \pm 1.19$ & $6.86 \pm 1.37$ & 0.819 \\
\hline Pain score $\mathbf{3 0} \mathrm{min}$ after wound closure & $3.86 \pm 1.93$ & $4.46 \pm 1.89$ & 0.043 \\
\hline Patients' satisfaction 15 min after drug injection & $1.44 \pm 0.52$ & $1.44 \pm 0.59$ & 0.991 \\
\hline Patients' satisfaction during wound closure & $2.79 \pm 0.97$ & $2.51 \pm 0.86$ & 0.335 \\
\hline Patients' satisfaction $6 \mathrm{~h}$ after wound closure & $3.98 \pm 1.02$ & $3.20 \pm 1.15$ & 0.000 \\
\hline
\end{tabular}

The mean \pm SD pain scores during the wound repair and before the application of local anesthesia (i.e. lidocaine) were similar in both intervention (6.91 \pm 1.19$)$ and control $(6.86 \pm 1.37)$ groups $(\mathrm{P}=0.81)$. However, the mean \pm SD pain score was significantly lower in patients who received Ibuprofen $(3.86 \pm 1.93)$, compared to those who received placebo (4.46 \pm 1.89$), 30 \mathrm{~min}$ after the wound repair $(\mathrm{P}=0.043)$. There was no statistically significant difference in patients' satisfaction of pain management 15 min after infusion and during the wound repair. However, the patients' satisfaction with pain management was higher in the intervention

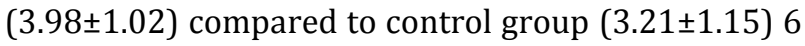
$\mathrm{h}$ after the wound repair. The difference between two groups in terms of pain severity was statistically significant $(\mathrm{P}=0.000)$. Table 2 presents the study results in detail. 


\section{Discussion}

Based on the obtained results, the use of IV Ibuprofen before wound closure was effective in the reduction of postoperative pain measured $30 \mathrm{~min}$ after the wound repair and increase of patients' satisfaction with analgesia $6 \mathrm{~h}$ after the wound repair. However, the use of IV Ibuprofen before wound closure was not effective in the reduction of pain at the time of wound repair, and the improvement of patients' satisfaction $15 \mathrm{~min}$ after infusion of IV Ibuprofen and during the wound repair. Based on previous studies on the pharmacokinetics of IV Ibuprofen, CSF concentration reached the peak within 30 to $38 \mathrm{~min}$ after the infusion $(16,22)$, and plasma concentration may take $1 \mathrm{~h}$ to reach the peak depending on infusion speed (23). This can explain how Ibuprofen showed more efficacy in late outcomes in this study.

Traumatic wound repair is a procedure accompanied by extra tissue damage, irrigated wound, and debridement. Suturing itself can cause inflammation, pain, and significant discomfort after the wound closure is completed. However, there is a dearth of data concerning pain reduction methods after wound repair. Our knowledge about the effect of NSAIDs on postoperative pain is limited to studies conducted on surgical wounds, and there are still some controversies over this issue. However, the results of another meta-analysis performed by Nir et al. including studies on different kinds of medication for pre-operative analgesias (e.g., opioids, NSAIDs, Gabapentin, Pregabalin, Clonidine, and Dextromethorphan) showed that although $\operatorname{COX} 2$ inhibitor class of NSAIDs were effective in the reduction of postoperative pain and rescue analgesics requirement, other classes of NSAIDs, including propionic acid class failed to show effectiveness in this regard. Four studies among the included studies in this metaanalysis used Ibuprofen in gynecology and dental surgeries (14). Singla N et al. conducted a multicenter RCT which showed that IV Ibuprofen $800 \mathrm{mg}$ used before the surgery and every $6 \mathrm{~h}$ after the surgery is effective in reducing pain in orthopedic surgeries. The findings showed that early postoperative pain would be significantly reduced in the group of intervention, compared to placebo after the patients received the single pre-operative dose of Ibuprofen (17). Moss JR et al. applied a single dose of $10 \mathrm{mg} / \mathrm{kg}$ IV Ibuprofen on 161 pediatric patients undergoing tonsillectomy before the induction of anesthesia which reduced the need for postoperative rescue analgesics (19). The application of single-dose IV Ibuprofen $400 \mathrm{mg}$ in another study showed that pre-operative Ibuprofen reduces postoperative pain measured by visual analog scale within a few minutes and up to $24 \mathrm{~h}$ after the surgery, and patients who received Ibuprofen required lower opioid and other analgesics after the surgery (21).

The results obtained in this study were consistent with the findings of most previous studies; although, this seems to be the first study on pre-operative use of Ibuprofen on traumatic wounds.

\section{Limitation}

Regarding the limitation of the present study, it should be noted that due to the fact that initial pain scores had not been recorded, it was not possible to calculate the change in pain severity following the traumatic wound repair. The probable side effects of Ibuprofen were not recorded as well. We are planning to conduct other studies in the future that lack the limitations of the present study in order to provide more evidence on this issue.

Therefore, regarding the lack of knowledge on pain management after traumatic wound repair, further studies on different classes of NSAIDs and other analgesics seem to be necessary.

\section{Conclusion}

Based on the obtained results, IV Ibuprofen is effective for the reduction of pain after the wound repair procedure in the emergency department of hospitals and health centers.

\section{Acknowledgments}

The authors are grateful to patients who willingly participated in this trial. We would like to thank the authorities in Iran University of Medical Sciences, Tehran, Iran, for their assistance and cooperation.

\section{Footnotes}

Authors' Contribution: HBG and MHR contributed to the acquisition of data, drafting the article, and interpretation of data. HS, EM, HBG and NA contributed to the conception and design and interpretation of data. All authors contributed to the initiation of the research and interpretation of data. HS, HBG and MHR contributed to the analysis and interpretation of data. NA and EM contributed to drafting the article and revising it critically for important intellectual content. All authors have read and approved the final version of the manuscript.

Funding/ Support: The authors received no funding or grant from any organization or institute in the public, private, or non-profit sector.

Conflicts of Interest: The authors declare that they have no conflict of interest regarding the publication of the present study.

Ethical Approval: This study was approved by the Ethics Committee of the Iran University of Medical Sciences, Tehran, Iran (IR.IUMS.FMD.REC 1396.9511307013). 


\section{References}

1. Rui P, Kang K, Ashman JJ. National hospital ambulatory medical care survey: 2016 emergency department summary tables. 2016. Atlanta, GA: Centers for Disease Control and Prevention; 2017.

2. Singer AJ, Mach C, Thode HC Jr, Hemachandra S, Shofer FS, Hollander JE. Patient priorities with traumatic lacerations. Am J Emerg Med. 2000;18(6):683-6. doi: 10.1053/ajem.2000.16312. [PubMed: 11043622].

3. Prevaldi C, Paolillo C, Locatelli C, Ricci G, Catena F, Ansaloni L, et al. Management of traumatic wounds in the Emergency Department: position paper from the Academy of Emergency Medicine and Care (AcEMC) and the World Society of Emergency Surgery (WSES). World J Emerg Surg. 2016;11:30. doi: 10.1186/s13017-016-0084-3. [PubMed: 27330546].

4. Nicks BA, Ayello EA, Woo K, Nitzki-George D, Sibbald RG. Acute wound management: revisiting the approach to assessment, irrigation, and closure considerations. Int J Emerg Med. 2010;3(4):399-407. doi: 10.1007/s12245-010-0217-5. [PubMed: $21373312]$.

5. De Buck F, Devroe S, Missant C, Van de Velde M. Regional anesthesia outside the operating room: indications and techniques. Curr Opin Anaesthesiol. 2012;25(4):501-7. doi: 10.1097/AC0.0b013e3283556f58. [PubMed: 22673788].

6. Davies RJ. Buffering the pain of local anaesthetics: a systematic review. Emerg Med (Fremantle). 2003;15(1):81-8. doi: 10.1046/j.1442-2026.2003.00413.x. [PubMed: 12656792].

7. Singer AJ, Hollander JE, Quinn JV. Evaluation and management of traumatic lacerations. N Engl J Med. 1997;337(16):1142-8. doi: 10.1056/NEJM199710163371607. [PubMed: 9329936].

8. Zempsky WT, Cravero JP; American Academy of Pediatrics Committee on Pediatric Emergency Medicine and Section on Anesthesiology and Pain Medicine. Relief of pain and anxiety in pediatric patients in emergency medical systems. Pediatrics. 2004;114(5):1348-56. doi: 10.1542/peds.2004-1752. [PubMed: 15520120].

9. Livingston A. Mechanism of action of nonsteroidal antiinflammatory drugs. Vet Clin North Am Small Anim Pract. 2000;30(4):773-81. doi: 10.1016/s0195-5616(08)70006-8. [PubMed: 10932824].

10. Díaz-González F, Sánchez-Madrid F. NSAIDs: learning new tricks from old drugs. Eur J Immunol. 2015;45(3):679-86. doi: 10.1002/eji.201445222. [PubMed: 25523026].

11. Michelet D, Andreu-Gallien J, Bensalah T, Hilly J, Wood C, Nivoche $Y$, et al. A meta-analysis of the use of nonsteroidal antiinflammatory drugs for pediatric postoperative pain. Anesth Analg. 2012;114(2):393-406. doi: 10.1213/ANE.0b013e31823d0b45. [PubMed: 22104069].

12. Costa FW, Esses DF, de Barros Silva PG, Carvalho FS, Sá CD, Albuquerque $\mathrm{AF}$, et al. Does the preemptive use of oral nonsteroidal anti-inflammatory drugs reduce postoperative pain in surgical removal of third molars? A meta-analysis of randomized clinical trials. Anesth Prog. 2015;62(2):57-63. doi:
10.2344/0003-3006-62.2.57. [PubMed: 26061574].

13. De Oliveira GS Jr, Agarwal D, Benzon HT. Perioperative single dose ketorolac to prevent postoperative pain: a meta-analysis of randomized trials. Anesth Analg. 2012;114(2):424-33. doi: 10.1213/ANE.0b013e3182334d68. [PubMed: 21965355].

14. Nir RR, Nahman-Averbuch H, Moont R, Sprecher E, Yarnitsky D. Preoperative preemptive drug administration for acute postoperative pain: a systematic review and meta-analysis. Eur J Pain. 2016;20(7):1025-43. doi: 10.1002/ejp.842. [PubMed: 26991963].

15. Bushra R, Aslam N. An overview of clinical pharmacology of Ibuprofen. Oman Med J. 2010;25(3):155-661. doi: 10.5001/omj.2010.49. [PubMed: 22043330].

16. Bookstaver PB, Miller AD, Rudisill CN, Norris LB. Intravenous ibuprofen: the first injectable product for the treatment of pain and fever. J Pain Res. 2010;3:67-79. doi: 10.2147/jpr.s6993. [PubMed: 21197311].

17. Singla N, Rock A, Pavliv L. A multi-center, randomized, doubleblind placebo-controlled trial of intravenous-ibuprofen (IVibuprofen) for treatment of pain in post-operative orthopedic adult patients. Pain Med. 2010;11(8):1284-93. doi: 10.1111/j.1526-4637.2010.00896.x. [PubMed: 20609131].

18. Pınar HU, Karaca Ö, Karakoç F, Doğan R. Effects of addition of preoperative intravenous ibuprofen to pregabalin on postoperative pain in posterior lumbar interbody fusion surgery. Pain Res Manag. 2017;2017:1030491. doi: 10.1155/2017/1030491. [PubMed: 28951663].

19. Moss JR, Watcha MF, Bendel LP, McCarthy DL, Witham SL, Glover CD. A multicenter, randomized, double-blind placebocontrolled, single dose trial of the safety and efficacy of intravenous ibuprofen for treatment of pain in pediatric patients undergoing tonsillectomy. Paediatr Anaesth. 2014; 24(5):483-9. doi: 10.1111/pan.12381. [PubMed: 24646068].

20. Çelik EC, Kara D, Koc E, Yayik AM. The comparison of singledose preemptive intravenous ibuprofen and paracetamol on postoperative pain scores and opioid consumption after open septorhinoplasty: a randomized controlled study. Eur Arch Otorhinolaryngol. 2018;275(9):2259-63. doi: 10.1007/s00405-018-5065-6. [PubMed: 30022362].

21. Ahiskalioglu EO, Ahiskalioglu A, Aydin P, Yayik AM, Temiz A. Effects of single-dose preemptive intravenous ibuprofen on postoperative opioid consumption and acute pain after laparoscopic cholecystectomy. Medicine (Baltimore). 2017; 96(8):e6200. doi: 10.1097/MD.0000000000006200. [PubMed: 28225506].

22. Kokki H, Kumpulainen E, Lehtonen M, Laisalmi M, Heikkinen M, Savolainen J, et al. Cerebrospinal fluid distribution of ibuprofen after intravenous administration in children. Pediatrics. 2007;120(4):e1002-8. doi: 10.1542/peds.2007-0064. [PubMed: 17908721].

23. Smith HS, Voss B. Pharmacokinetics of intravenous ibuprofen: implications of time of infusion in the treatment of pain and fever. Drugs. 2012;72(3):327-37. doi: 10.2165/11599230000000000-00000. [PubMed: 22316349]. 